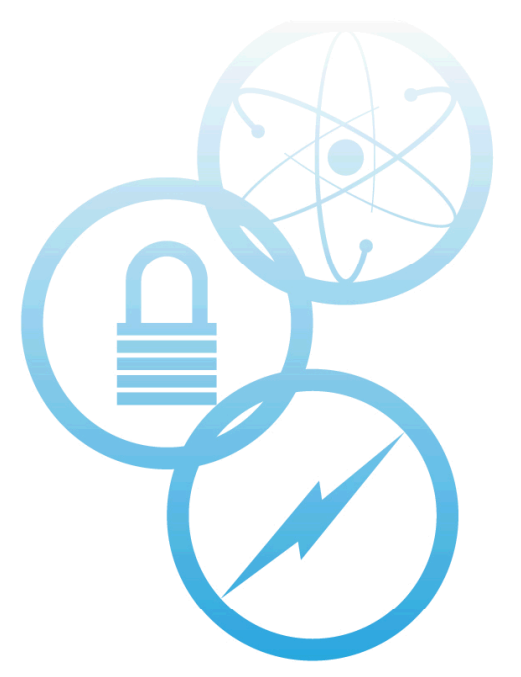

\title{
Milestone 2.6: Complete Round-Robin Hydrogen Gas Analysis Capability Comparison
}

Gregory P. Horne and Elizabeth H. Parker-Quaife

Idaho National Laboratory, Center for Radiation Chemistry Research

Christopher G. Verst, Charles L. Crawford, Robert L. Sindelar

Savannah River National Laboratory

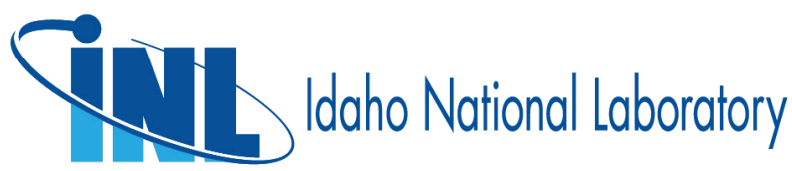




\section{DISCLAIMER}

This information was prepared as an account of work sponsored by an agency of the U.S. Government. Neither the U.S. Government nor any agency thereof, nor any of their employees, makes any warranty, expressed or implied, or assumes any legal liability or responsibility for the accuracy, completeness, or usefulness, of any information, apparatus, product, or process disclosed, or represents that its use would not infringe privately owned rights. References herein to any specific commercial product, process, or service by trade name, trade mark, manufacturer, or otherwise, does not necessarily constitute or imply its endorsement, recommendation, or favoring by the U.S. Government or any agency thereof. The views and opinions of authors expressed herein do not necessarily state or reflect those of the U.S. Government or any agency thereof. 
INL/EXT-20-60698

Revision 0

\title{
Milestone 2.6: Complete Round-Robin Hydrogen Gas Analysis Capability Comparison
}

\author{
Gregory P. Horne and Elizabeth H. Parker-Quaife \\ Idaho National Laboratory, Center for Radiation Chemistry Research \\ Christopher G. Verst, Charles L. Crawford, and Robert L. Sindelar \\ Savannah River National Laboratory
}

November 2020

\author{
Idaho National Laboratory \\ Center for Radiation Chemistry Research \\ Idaho Falls, Idaho 83415
}

http://www.inl.gov

Prepared for the

U.S. Department of Energy

Office of Environmental Management

Under DOE Idaho Operations Office

Contract DE-AC07-05ID14517 
Page intentionally left blank 


\begin{abstract}
The Department of Energy (DOE) is currently evaluating strategies for the extended dry storage of aluminum-clad spent nuclear fuel (ASNF). Part of this assessment concerns the extent of radiolytic molecular hydrogen $\left(\mathrm{H}_{2}\right)$ generation from the aluminum cladding's oxyhydroxide corrosion layers. Understanding this radiation-induced process and the factors affecting it (e.g., system conditions such as temperature and gaseous environment) are essential for the development of predictive computer models to support the Technical Considerations and Challenges for Extended ( $>50$ yrs) Dry Storage of ASNF program. To achieve this goal and ensure that the experimental data gathered by Task 2 (Oxyhydroxide Layer Radiolytic Gas Generation Resolution) research groups (Idaho National Laboratory and Savannah River National Laboratory) are consistent, a round-robin $\mathrm{H}_{2}$ analysis capability comparison was initiated. Here we present the results from said round robin and conclude that despite differences in sample preparation, irradiation parameters, and analytical procedures, the measured data are sufficiently consistent between the two laboratories $(\leq 15 \%)$.
\end{abstract}


Page intentionally left blank 


\section{CONTENTS}

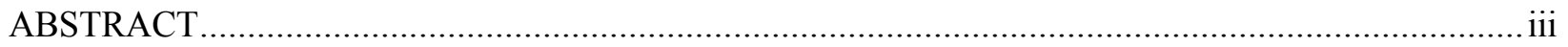

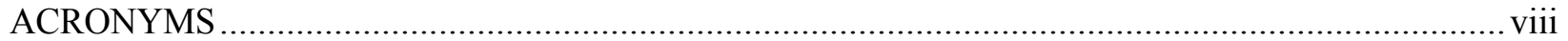

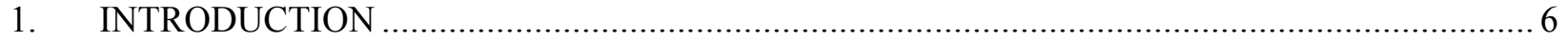

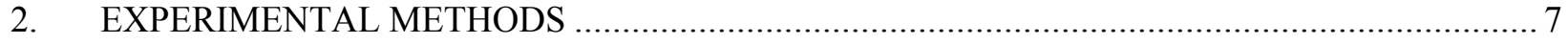

$2.1 \quad$ INL Gamma Irradiations and Sample Analysis …...................................................... 7

2.2 SRNL Gamma Irradiations and Sample Analysis ...................................................... 7

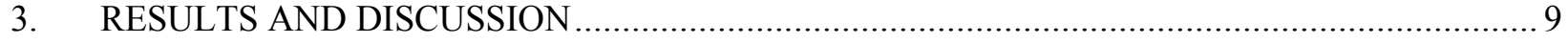

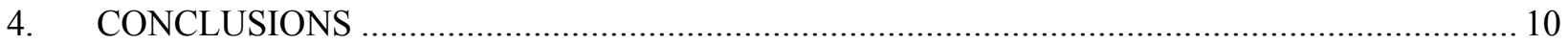

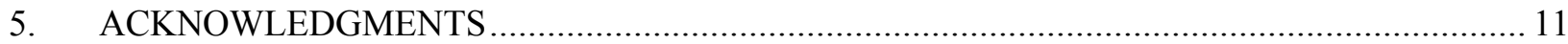

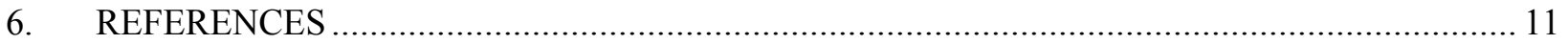




\section{FIGURES}

Figure 1. (A) The SRNL 'crush tube' metal manifold provides a consistent volume and known pressure from which to pull samples into the GC. (B) Ampules are loaded into the central sanitary flange which is sealed with a re-usable rubber gasket. The flange body is modified to include a gas tight threaded punch which crushes the ampule when

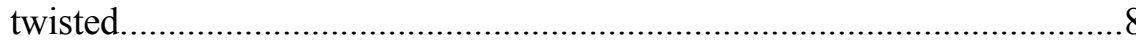

\section{TABLES}

Table 1. Comparison of $\mathrm{H}_{2} \mathrm{G}$-values from the irradiation of pre-corroded Al-1100 coupons flame sealed in argon environments at $0 \%$ relative humidity

Table 2. Comparison of corrosion layer oxide thickness on pre-corroded Al-1100 coupons, assuming the layer consists of either a single boehmite or bayerite mineral phase. Thicknesses were calculated using equations adapted from Lister [24] 
Page intentionally left blank 


\section{ACRONYMS}

$\begin{array}{lll}\text { Al-1100 } & - & \text { aluminum alloy } 1100 \\ \text { ASNF } & - & \text { aluminum-clad spent nuclear fuel } \\ \text { GC } & - & \text { gas chromatography } \\ \mathrm{Gy} \mathrm{min}^{-1} & - & \text { Grays per minute } \\ \mathrm{H}_{2} & - & \text { molecular hydrogen } \\ \mathrm{ID} & - & \text { inner diameter } \\ \mathrm{INL} & - & \text { Idaho National Laboratory } \\ \mathrm{kGy} & - & \text { kilo Gray } \\ \mathrm{kPa} & - & \text { kilopascals } \\ \mathrm{L} & - & \text { length } \\ \mathrm{OD} & - & \text { outer diameter } \\ \mathrm{ppm} & - & \text { parts per million } \\ \mathrm{PTFE} & - & \text { polytetrafluoroethylene } \\ \mathrm{SRNL} & - & \text { Savannah River National Laboratory } \\ \mathrm{TCD} & - & \text { thermal conductivity detector } \\ \mathrm{yrs} & - & \text { years } \\ { }^{\circ} \mathrm{C} & - & \text { degrees Celsius } \\ \mu \mathrm{L} & - & \text { microliter } \\ \mu \mathrm{m} & - & \text { micrometer } \\ \mu \mathrm{mol} \mathrm{J} & -1 & \text { micromoles per Joule } \\ & - & \end{array}$


Page intentionally left blank 


\section{INTRODUCTION}

Aluminum-based alloys have been used extensively in the United States as nuclear fuel cladding for a variety of different reactors [1]. Consequently, a significant amount ( $\sim 13$ metric tons) of aluminum-clad spent nuclear fuel (ASNF) has been accumulated without a final storage solution. Current efforts to resolve this challenge are focused on long-term ( $>50$ years) dry storage of the fuel in bespoke canisters [2-4]. However, this strategy necessitates an understanding of the extent of radiolytic molecular hydrogen $\left(\mathrm{H}_{2}\right)$ generation from the fuel's corroded surface due to the proposed canister design's internal pressure limitations [2-4]. This understanding is currently being developed under Task 2 (Oxyhydroxide Layer Radiolytic Gas Generation Resolution) of the Technical Considerations and Challenges for Extended ( $>$ 50 yrs) Dry Storage of ASNF program.

The combination of in-reactor conditions and subsequent wet storage in cooling ponds has promoted the formation of hydrated aluminum corrosion layers on the ASNF elements [1]. These layers are typically a mixture of aluminum oxyhydroxide mineral phases (e.g., boehmite, gibbsite, and bayerite), the composition and thickness of which are dependent on a given fuel element's service history [1]. Nevertheless, these layers have been implicated in the radiolytic formation of $\mathrm{H}_{2}$ [5-8,9], which could lead to canister pressurization and subsequent physical stresses [10]. Further, $\mathrm{H}_{2}$ has been shown to promote embrittlement of aluminum [11-13], which may compromise the integrity of the cladding itself. The source of $\mathrm{H}_{2}$ is believed to originate from a combination of (i) physi/chemisorbed water radiolysis $[14,15]$ and (ii) surface-mediated processes arising from energy migration from radiation absorbed by the bulk material and then transferred to the surface corrosion layers [16,17]. Task 2 has recently demonstrated that these radiolytic $\mathrm{H}_{2}$ formation pathways are influenced by gaseous environment composition, relative humidity, and temperature [9], all parameters of import for the evaluation of proposed long-term dry storage canister design.

Subsequent Task 2 studies have brought to light subtle differences between the Task 2 research groups'-Idaho National Laboratory (INL) and Savannah River National Laboratory (SRNL) experimental methodologies. If unchecked, these differences could lead to erroneous data, which may hamper the development of predictive modeling capabilities under Task 3 (Sealed and Vented System Episodic Breathing and Gas Generation Prediction). To determine the impact of these experimental differences on the reported yields of $\mathrm{H}_{2}$, a round-robin $\mathrm{H}_{2}$ analysis capability comparison was initiated. The focus of this report is the evaluation of each research group's experimental methodology - sample preparation, corrosion procedure, irradiation parameters, and analytical techniques — on the final reported radiolytic yield for $\mathrm{H}_{2}$ production. 


\section{EXPERIMENTAL METHODS}

\subsection{INL Gamma Irradiations and Sample Analysis}

Aluminum alloy 1100 coupons (Al-1100) were purchased from Metals Samples Company Alabama Specialty Products Inc. Acetone (HPLC Plus, $\geq 99.9 \%$ ), ethanol (absolute, $\geq 99.8 \%$ ), iron(II) sulfate heptahydrate ( $\geq 99 \%$ ), and sulfuric acid (99.999\%) were supplied by MilliporeSigma. Argon was purchased in its highest available purity from Norco. All applications of water used ultra-pure water $(18.2 \mathrm{M} \Omega \mathrm{cm})$. All Al-1100 coupons were cleaned, weighed, pre-corroded, and weighed again as previously described [9].

Gamma irradiations were performed using the new Center for Radiation Chemistry Research Foss Therapy Services Cobalt-60 Irradiator unit. INL sample preparation (\#102, 104, 105, and 106) was as previously reported [9], affording pre-corroded Al-1100 coupons $(2.5 \mathrm{~cm} \times 0.65 \mathrm{~cm} \times 0.15 \mathrm{~cm})$ individually flame sealed in glass ampules containing an argon gaseous environment at $0 \%$ relative humidity. Both INL (\#102, 104, 105, and 106) and SRNL (\#201, 203, 205, and 206) samples were loaded into a bespoke multi-position sample holder and irradiated at ambient irradiator temperature $\left(\sim 45^{\circ} \mathrm{C}\right.$, as measured by a calibrated NI USB-TC01 Single Channel Temperature Input Device using K-type thermocouples). These irradiations took place over several days to achieve the desired absorbed gamma doses at a dose rate of between 50 and $175 \mathrm{~Gy} \mathrm{~min}^{-1}$, as dictated by sample position. Dosimetry was determined using Fricke solution $[18,19]$ for each sample position, corrected for ${ }^{60} \mathrm{Co}$ decay $\left(\tau_{1 / 2}=5.27\right.$ years; $\mathrm{E}_{\gamma 1}=1.17 \mathrm{MeV}$ and $\mathrm{E}_{\gamma 1}=1.33 \mathrm{MeV}$ ) and aluminum electron density (0.8673) [20]. Half of the irradiated coupons (\#104, 106, 205, and 206) were then shipped to SRNL for $\mathrm{H}_{2}$ analysis.

The remaining irradiated INL samples (\#102, 105, 201, and 203) and irradiated samples received from SRNL (\#219, 220, and 221) were analyzed for $\mathrm{H}_{2}$ by gas chromatography (GC) using a previously described "crush tube" method with an SRI 8610 model gas chromatograph equipped with a thermal conductivity detector (TCD) [9]. This method has an estimated error of $\leq 5 \%$ and a $\mathrm{H}_{2}$ sensitivity limit of $1.0 \mu \mathrm{L}[9,21,22]$.

\subsection{SRNL Gamma Irradiations and Sample Analysis}

Aluminum alloy 1100 coupons (Al-1100) were purchased from Metals Samples Company Alabama Specialty Products Inc. Acetone $(\geq 99.0 \%)$ and ethanol $(\geq 99.8 \%)$ were supplied by SigmaAldrich and Arcos Organics, respectively. Ultra-high purity argon (99.9998\%) was purchased from nexAir. All applications of water used ultra-pure water $(18.0 \mathrm{M} \Omega \mathrm{cm})$.

The Al-1100 coupons were sonicated in sequential baths of acetone, ethanol, and water. Cleaned samples were then air dried for 24 hours before being weighed. Pre-corrosion was achieved by independently loading cleaned coupons into model 4749 Parr vessels, each containing a $23 \mathrm{~mL}$ PTFE cup filled with $15 \mathrm{~mL}$ of water. The sealed Parr vessels were then loaded into an oven pre-heated to $185^{\circ} \mathrm{C}$ and left for $\sim 18$ hours. The Parr vessels were then removed and allowed to cool for 2 hours at ambient temperature prior to removing the corroded coupons, which were then set aside to air dry overnight before being re-weighed. This corrosion process was performed in batches of four coupons. Consequently, there is some variability in the amount of time that coupons spent idle between cleaning, corroding, and being irradiated. Recorded weights reflect measurements taken immediately preceding each step. Half of the corroded coupons were shipped to INL (\#201, 203, 205, and 206) to be flame sealed, irradiated, and analyzed for $\mathrm{H}_{2}$. The remaining coupons (\#219, 220, 221, 224, 225, and 226) were flame sealed and irradiated at SRNL.

Gamma irradiations were performed using a J.L. Shepherd Model 109-68R Co-60 gamma irradiator unit. SRNL samples for irradiation were prepared by flame sealing pre-corroded coupons in pre-baked 
$\left(350^{\circ} \mathrm{C}\right)$ Pyrex ampules $(10 \mathrm{~mm}$ OD $\times 8 \mathrm{~mm} \mathrm{ID} \times 85 \mathrm{~mm} \mathrm{~L})$ using a glass Schlenk Line. All ampules were repeatedly evacuated and backfilled with dry argon gas prior to being flame sealed. A blank ampule containing no sample was included in each batch of sealed coupons and then evaluated using GC to ensure that no oxygen or nitrogen was present in the Schlenk line at the time of sealing. These samples $(\# 219,220,221,224,225$, and 226$)$ were irradiated at ambient irradiator temperature $\left(\sim 23.5^{\circ} \mathrm{C}\right.$, as measured by a calibrated Fluke 714 thermocouple calibrator using K-type thermocouples) for a period of 640 hours. A sample dose rate of $8.3 \mathrm{~Gy} \mathrm{~min}^{-1}$ was determined by Fricke dosimetry $[18,19]$ corrected for radioactive decay and aluminum electron density. Half of the irradiated coupons $(\# 219,220$, and 221) were then shipped to INL for $\mathrm{H}_{2}$ analysis.

The remaining irradiated SRNL samples (\#224, 225, and 226) and irradiated samples received from INL (\#104, 105, 205, and 206) were analyzed for $\mathrm{H}_{2}$ by GC using an Inficon 3000 Micro GC. The GC utilized a 10-m molecular sieve column with ultra-high-purity (99.999\%) argon carrier gas. Ampules were cracked using a bespoke, resealable metal manifold featuring an argon gas inlet, manometer exhaust, in-line pressure transducer, and outlet line to the GC sample port, shown in Figure 1.

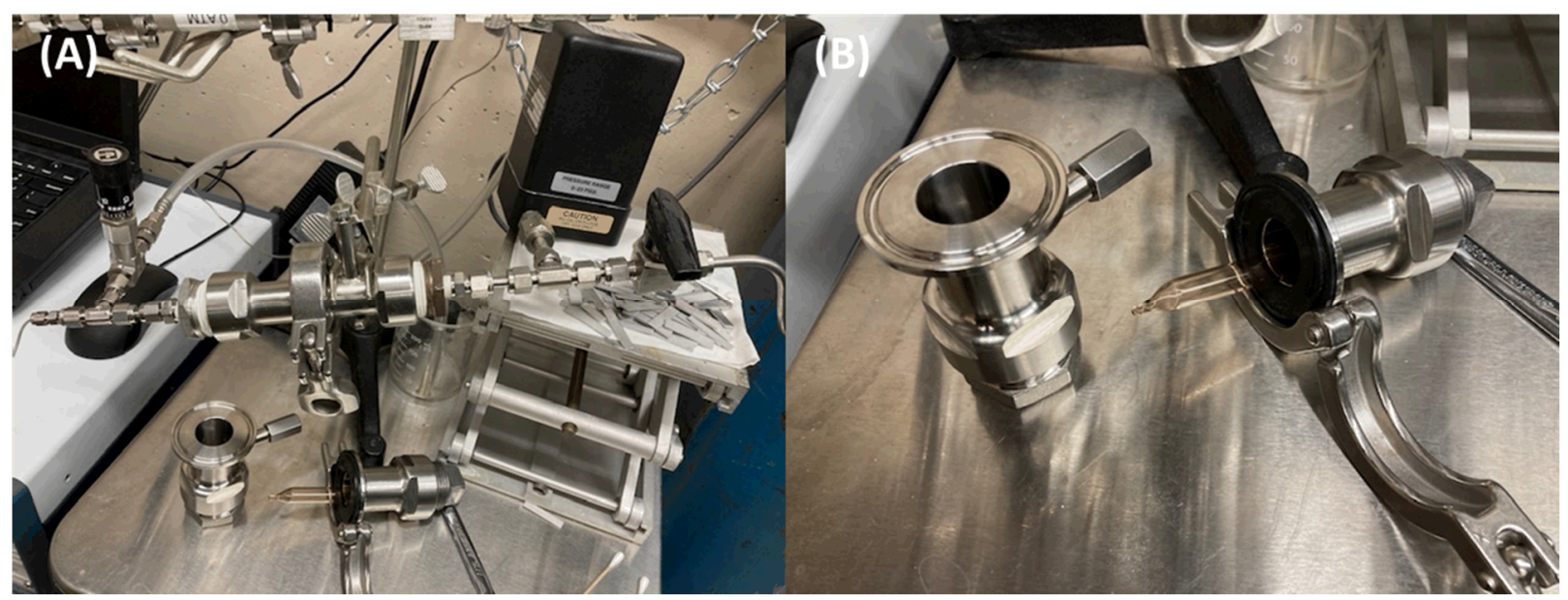

Figure 1. (A) The SRNL "crush tube" metal manifold provides a consistent volume and known pressure from which to pull samples into the GC. (B) Ampules are loaded into the central sanitary flange, which is sealed with a re-usable rubber gasket. The flange body is modified to include a gas-tight threaded punch, which crushes the ampule when twisted.

The manifold is loaded with an ampule, purged with argon, and slightly pressurized to provide enough inlet pressure for multiple GC samples to be taken. An ampule is then cracked using a threaded punch which penetrates the vessel, after which sequential small-volume samples are automatically injected into the $\mathrm{GC}$ to quantify the amount of $\mathrm{H}_{2}$ present. Calibration of the $\mathrm{GC}$ response to $\mathrm{H}_{2}$ was performed by injecting gas standards-(i) $50.5 \mathrm{ppm} \mathrm{H}_{2}, 20.0 \% \mathrm{O}_{2}$, balance $\mathrm{N}_{2}, 25.1 \% \mathrm{CO}_{2}$, and (ii) $102 \mathrm{ppm}_{2}, 2.52 \%$ $\mathrm{N}_{2} \mathrm{O}, 15.0 \% \mathrm{O}_{2}$, balance $\mathrm{N}_{2}$ - directly into the GC and correlating to TCD signal area. The moles of $\mathrm{H}_{2}$ released into the manifold from each cracked ampule were calculated from the average of three consecutive GC samples using the calibration, manifold volume, and the measured manifold pressure at the time of sampling. This method has an estimated error of $\leq 4 \%$ and a $\mathrm{H}_{2}$ sensitivity limit of $1.0 \mu \mathrm{L}$. 


\section{RESULTS AND DISCUSSION}

A comparison of experimental data measured by this work is given in Table 1 . Three different dose regimes $(308.32,449.22$, and $487.33 \mathrm{kGy})$ were investigated with samples being prepared, irradiated, and analyzed at both institutions to evaluate the consistency of their respective methodologies.

Table 1. Comparison of $\mathrm{H}_{2} G$-values from the irradiation of pre-corroded Al-1100 coupons flame sealed in argon environments at $0 \%$ relative humidity.

\begin{tabular}{|c|c|c|c|c|c|c|c|}
\hline$\#$ & $\begin{array}{l}\text { Sample } \\
\text { preparation }\end{array}$ & $\begin{array}{l}\text { Irradiation } \\
\text { facility }\end{array}$ & Analysis & $\begin{array}{l}\boldsymbol{\gamma} \text {-dose } \\
(\mathrm{kGy})\end{array}$ & $\begin{array}{l}\boldsymbol{G} \text {-value } \\
\left(\mu \mathrm{mol} \mathrm{J}{ }^{-1}\right)\end{array}$ & $\begin{array}{l}\text { Average } \\
\boldsymbol{G} \text {-value } \\
\left(\mu \mathrm{mol} \mathrm{J}{ }^{-1}\right)\end{array}$ & $\begin{array}{l}\text { Standard } \\
\text { deviation } \\
(\%)\end{array}$ \\
\hline 102 & INL & INL & INL & \multirow{4}{*}{449.22} & $7.66 \times 10^{-4}$ & \multirow{4}{*}{$7.29 \times 10^{-4}$} & \multirow{4}{*}{9.83} \\
\hline 105 & INL & INL & INL & & $8.18 \times 10^{-4}$ & & \\
\hline 104 & INL & INL & SRNL & & $6.25 \times 10^{-4}$ & & \\
\hline 106 & INL & INL & SRNL & & $7.06 \times 10^{-4}$ & & \\
\hline 201 & SRNL & INL & INL & \multirow{4}{*}{487.33} & $9.14 \times 10^{-4}$ & \multirow{4}{*}{$8.36 \times 10^{-4}$} & \multirow{4}{*}{9.57} \\
\hline 203 & SRNL & INL & INL & & $9.13 \times 10^{-4}$ & & \\
\hline 205 & SRNL & INL & SRNL & & $7.31 \times 10^{-4}$ & & \\
\hline 206 & SRNL & INL & SRNL & & $7.86 \times 10^{-4}$ & & \\
\hline 219 & SRNL & SRNL & INL & \multirow{7}{*}{308.32} & $9.94 \times 10^{-4}$ & \multirow{7}{*}{$8.24 \times 10^{-4}$} & \multirow{7}{*}{15.06} \\
\hline 220 & SRNL & SRNL & INL & & $9.48 \times 10^{-4}$ & & \\
\hline 221 & SRNL & SRNL & INL & & $8.98 \times 10^{-4}$ & & \\
\hline 223 & SRNL & SRNL & SRNL & & $7.36 \times 10^{-4}$ & & \\
\hline 224 & SRNL & SRNL & SRNL & & $8.37 \times 10^{-4}$ & & \\
\hline 225 & SRNL & SRNL & SRNL & & $6.15 \times 10^{-4}$ & & \\
\hline 226 & SRNL & SRNL & SRNL & & $7.43 \times 10^{-4}$ & & \\
\hline
\end{tabular}

Within the investigated dose regime, the radiolytic production of $\mathrm{H}_{2}$ has been previously shown to exhibit a linear relationship with absorbed gamma dose, which can be best described by a $G$-value [9] - the radiolytic yield, expressed in SI units of $\mu \mathrm{mol} \mathrm{J} \mathrm{J}^{-1}$. For pre-corroded Al-1100 coupons in argon at $0 \%$ relative humidity, our previous multi-dose point data set yielded a $G\left(\mathrm{H}_{2}\right)$ value of $7.3 \times 10^{-4} \mu \mathrm{mol} \mathrm{J}{ }^{-1}$ [9]. Here, all three averaged round-robin $G$-values (Table 1) are within $9 \%$ of their respective average-7.96 $\times 10^{-4} \mu \mathrm{mol} \mathrm{\textrm {J } ^ { - 1 }}$ - which is only $8 \%$ above our previously reported value. Thus, the reported data are in good agreement with our previous measurements, especially considering that these data are single point fits arising from different preparation and irradiation procedures. This is evident from the $\sim 26 \%$ variance in oxide layer thickness shown in Table 2. Oxide thickness was calculated for both boehmite and bayerite mineral phases due to the differences in temperature between the INL and SRNL corrosion procedures, 95 vs. $185^{\circ} \mathrm{C}$, respectively, with boehmite being the preferred oxyhydroxide at temperatures exceeding $\sim 100^{\circ} \mathrm{C} . \quad[23,24]$. 
Table 2. Comparison of corrosion layer oxide thickness on pre-corroded Al-1100 coupons, assuming the layer consists of either a single boehmite or bayerite mineral phase. Thicknesses were calculated using equations adapted from Lister [25].

\begin{tabular}{l|l|l|l|}
\hline$\#$ & Sample preparation & $\begin{array}{l}\text { Oxide thickness }(\mu \mathrm{m} \\
\text { assuming boehmite })\end{array}$ & $\begin{array}{l}\text { Oxide thickness }(\mu \mathrm{m} \\
\text { assuming bayerite })\end{array}$ \\
\hline $\mathbf{1 0 2}$ & INL & 1.88 & 2.23 \\
\hline $\mathbf{1 0 5}$ & INL & 1.97 & 2.34 \\
\hline $\mathbf{1 0 4}$ & INL & 1.85 & 2.20 \\
\hline $\mathbf{1 0 6}$ & INL & 2.27 & 1.92 \\
\hline $\mathbf{2 0 1}$ & SRNL & 1.62 & 1.91 \\
\hline $\mathbf{2 0 3}$ & SRNL & 1.62 & 1.92 \\
\hline $\mathbf{2 0 5}$ & SRNL & 1.58 & 1.87 \\
\hline $\mathbf{2 0 6}$ & SRNL & 1.77 & 2.10 \\
\hline $\mathbf{2 1 9}$ & SRNL & 1.59 & 1.89 \\
\hline $\mathbf{2 2 0}$ & SRNL & 1.48 & 1.75 \\
\hline $\mathbf{2 2 1}$ & SRNL & 1.59 & 1.88 \\
\hline $\mathbf{2 2 3}$ & SRNL & 1.36 & 1.61 \\
\hline $\mathbf{2 2 4}$ & SRNL & 1.87 & 2.22 \\
\hline $\mathbf{2 2 5}$ & SRNL & 2.25 & 2.67 \\
\hline $\mathbf{2 2 6}$ & SRNL & 1.75 & 2.07 \\
\hline
\end{tabular}

Interestingly, the SRNL measured $G$-values are consistently lower than the corresponding INL measured $G$-values, as shown in Table 1. This trend is independent of sample preparation and irradiation origin, indicating that the discrepancy is in the analytical methodology. This trend may be due to the SRNL analytical approach exhibiting an internal manifold pressure dependence on the value of $\mathrm{H}_{2}$ quantified, requiring each data point to be an average of 3 out of 5 measurements per ampule. Whereas the INL GC method takes a single measurement per ampule, sampling the entire gaseous phase. However, given the relatively low associated deviation between data sets $(\leq 15 \%)$, the presented $G\left(\mathrm{H}_{2}\right)$ data demonstrate acceptable experimental consistency between the two institutions.

\section{CONCLUSIONS}

The purpose of this investigation was to evaluate the consistency of experimental methodologies between the Task 2 (Oxyhydroxide Layer Radiolytic Gas Generation Resolution) research groups (INL and SRNL), so as to ensure that radiolytic $\mathrm{H}_{2}$ data provided is sufficiently accurate for the development and evaluation of predictive computer models to support the Technical Considerations and Challenges for Extended (> 50 yrs) Dry Storage of ASNF program. Although experimental methods still vary subtly, and there is a consistent difference between the measured $G$-values from both institutions, the presented data demonstrate that these differences are relatively small, amounting to $\leq 15 \%$, and are not expected to compromise the validity of future experiments. 


\section{ACKNOWLEDGMENTS}

This work was supported by the U.S. Department of Environmental Management, Office of Technology Development, under contract DE-AC07-05ID14517.

\section{REFERENCES}

(1) Corrosion of Research Reactor Aluminium Clad Spent Nuclear Fuel in Water. IAEATECDOC1637, 2009.

(2) United States Department of Energy, 1998a. Preliminary Design, Specification for Department of Energy Standardized Spent Nuclear Fuel Canisters. Idaho Falls, Vol I Design Specification.

(3) ECAR 4632, Spencer Snow, Supplemental Evaluation of the DOE Standard SNF Canister for Accidental Drops, 8/2019.

(4) United States Department of Energy, 1998b. Preliminary Design, Specification for Department of Energy Standardized Spent Nuclear Fuel Canisters. Idaho Falls, Vol II Rationale document.

(5) Wittman, R. Radiolysis Model Sensitivity Analysis for a Used Fuel Storage Canister. FCRD-UFD2013-000357, 2013.

(6) Wittman, R.S., Hanson, B.D., Radiolysis Model Analysis for a Used Fuel Storage Canister. IHLRWM, 2015.

(7) Elliot, A.J., Bartels, D.M., 2009. The Reaction Set, Rate Constants and G-Values for the Simulation of the Radiolysis of Light Water Over the Range $20^{\circ}$ to $350^{\circ} \mathrm{C}$ Based on Information Available in 2008. AECL Nuclear Platform Research and Development - Report 153-127160-450-001.

(8) $\mathrm{Hu}, \mathrm{T} . \mathrm{A} ., 2$ 2012. Improved Model for Hydrogen Generation Rate of Radioactive Waste at the Hanford Site. Nucl. Tech., 178, 39-54, DOI: 10.13182/NT12-A13546.

(9) Parker-Quaife, E.H., Verst, C., Heathman, C.R., Zalupski, P.Z., Horne, G.P., 2020. RadiationInduced Molecular Hydrogen Gas Generation in the Presence of Aluminum Alloy 1100. Rad. Phys. Chem., 77, 109117, DOI: 10.1016/j.radphyschem.2020.109117.

(10) Bonin, B., Colin, M., Dutfoy, A., 2000. Pressure Building During the Early States of Gas Production in a Radioactive Waste Repository. J. Nucl. Mater., 281, 1-14, DOI: 10.1016/S00223115(00)00184-7.

(11) Ambat, R., Dwaarakadasa, E.S., 1996. Effect of hydrogen in aluminium and aluminium alloys: a review. Bull. Mater. Sci., 19, 103-114, DOI: 10.1007/BF02744792.

(12) Gangloff, R.P., Somerday, B.P., 2012. Gaseous Hydrogen Embrittlement of Materials in Energy Technologies, Volume 1 - the Problem, its Characterization and Effects on Particular Alloy Classes. Elsevier, New York.

(13) Lu, G., Kaxiras, E., 2005. Hydrogen embrittlement of aluminum: the crucial role of vacancies. Phys. Rev. Lett., 94, 155501-155503, DOI: 10.1103/PhysRevLett.94.155501.

(14) Milosavljevic, B.H., Thomas, J.K., 2003. Reactions of electrons on the surface of $\gamma-\mathrm{Al}_{2} \mathrm{O}_{3}$. A pulse radiolytic study with $0.4 \mathrm{MeV}$ electrons. J. Phys. Chem. B, 107, 11907-11910, DOI: 10.1021/jp030348r.

(15) Thomas, J.K., 2005. Physical aspects of radiation-induced processes on $\mathrm{SiO}_{2}, \gamma-\mathrm{Al}_{2} \mathrm{O}_{3}$, Zeolites, and Clays. Chem. Rev., 105, 1683-1734, DOI: 10.1021/cr020378a.

(16) Kuruc, J., 1991. Paramagnetic centers by X-ray-irradiations of aluminium hydroxide EPR spectroscopy, radiation chemical yield and kinetics of thermal decay of paramagnetic centers. $J$. Radioanal. Nucl. Chem., 154, 61-72, DOI: 10.1007/BF02163064.

(17) Jones, B.M., Aleksandrov, A., Zhang, X., Rosso, K.M., Orlando, T.M., 2019. Electron- and thermal-stimulated synthesis of water on boehmite $(\gamma-\mathrm{AlOOH})$ nanoplates. J. Phys. Chem. C, 123 (31), 18986-18992, DOI: 10.1021/acs.jpcc.9b03927. 
(18) Fricke H., Hart, E.J., 1935. The Oxidation of $\mathrm{Fe} 2+$ to $\mathrm{Fe} 3+$ by the Irradiation with $X$-Rays of Solutions of Ferrous Sulfate in Sulfuric Acid. J. Chem. Phys., 3, 60-61, DOI: 10.1063/1.1749558.

(19) Barr, N.F., Schuler, R.H., 1959. The Dependence of Radical and Molecular Yields on Linear Energy Transfer in the Radiation Decomposition of $0.8 \mathrm{~N}$ Sulfuric Acid Solutions. J. Phys. Chem., 63, 808-813, DOI: 10.1021/j150576a008.

(20) Spinks J.W.T., Woods, R.J., An Introduction to Radiation Chemistry, Third Edition, WileyInterscience, New York, 1990.

(21) LaVerne, J.A., Huestis, P.L., 2019. H atom production and reaction in the gamma radiolysis of thermally modified boehmite. J. Phys. Chem. C, 123 (34), 21005-21010, DOI: 10.1021/acs.jpcc.9b05935.

(22) LaVerne, J.A., Schuler, R.H., 1984. Track effects in radiation chemistry: core processes in heavyparticle tracks as manifest by the hydrogen yield in benzene radiolysis. J. Phys. Chem., 88, 12001205, DOI: 10.1021/j150650a037.

(23) Lundberg, L., 1994. Corrosion of Spent ATR Fuel Elements Relative to Their Dry Storage. ERANRE-94-096, EG\&G.

(24) Glazoff, M.V., Lister, T.E., 2018. Transition of Spent Nuclear Fuel to Dry Storage, INL/EXT-1851694. Idaho National Laboratory.

(25) Lister, T.E., 2018. Vapor Phase Corrosion Testing of Pretreated Al1 100, INL/EXT-18-52249. 